\title{
A Brief Research on Social Organization Standards Top Runner System
}

\author{
Qing $\mathrm{Xu}{ }^{\mathrm{a}}$, Lianchao $\mathrm{Yu}^{\mathrm{b}}$ \\ China National Institute of Standardization, Beijing 100191, China \\ axuqing@cnis.gov.cn, byulch@cnis.gov.cn
}

Keywords: Top runner, social organization standards, third-party evaluation, reform of system

\begin{abstract}
Social organization standards top runner scheme is another brand-new territory after environmental protection, energy efficiency, water efficiency, enterprise standard top runner system. Social organization standards top runner scheme is aimed at setting good examples and guiding others in the social organization standards territory. The advancement of top runner scheme social organization standards is reflected in leading Indicators, leading technical level, good Implementation efficiency good, being leading role. This paper is aimed at researching and analyzing the working framework of China's social organization standards top runner system from three aspects of definition and scope, certification process and indicator system, supervision and management mechanism with the enlightenment of foreign and domestic top runner systems. The third-party evaluation mechanism of social organization standards top runner scheme is suggested and explored, viewing to providing theoretical support and reference thinking for China's social organization standards top runner system.
\end{abstract}

\section{Introduction}

Social organization standardization, with innate advantages of voluntariness, quick responsiveness to market and innovation, is the important measure of China's reform of standardization system. The effect of social organization standards on industry development is main about promotion of scientific and technological innovation, guidance on industrial distribution, promotion on trade contacts and so on $^{[1]}$. Japan issued energy efficiency Top Runner System in 1988 and the core content of the system is energy efficiency standards ${ }^{[2]}$.

The Plan for Furthering the Standardization reforms (Reform Plan for short) has issued more than a year until now. Some effects of China's social organization standardization have been made and many problems are faced likewise. This paper is aimed at researching and analyzing the working framework of China's social organization standards top runner system. The the third-party evaluation mechanism of social organization standards top runner scheme is suggested and explored, viewing to providing theoretical support and reference thinking for China's social organization standards top runner system.

\section{Social organization standards top runner system's working framework}

\subsection{Top runner system's definition and scope}

Social organization standards of top runner refer to product standards or technical standards with leading Indicators, leading technical level, good implementation efficiency good, leading role within the same kind. Social organizations are guided and stimulated to develop and implement advanced standards by carrying out social organization standards top runner system. Scientific and technological achievements can transform to standards in order to reinforce the supply of advanced standards and foster a batch of international advanced level social organization standards. The leading role of social organization standards top runner system shall be fully expressed to set good examples, guide others in the same territory and guide customers to choose high quality products. Social organization standards top runner system refers to standards, Social organization standards top runner products and organizations are derived by top runner standards.

The scope of social organization standards top runner system shall be limited to the same kind and have comparability. In the initial stage of top runner system, territories with high marketization, active 
technological innovation and more product standards shall be chosen to be experimental units. Investigate and survey will be carried out at experimental units and standard category will be divided. Then the specific indexes can be set so that the social organization standards will have comparability. And this will lay the foundation of social organization standards top runner system's popularization nationwide.

\subsection{The certification process and indicator system of top runner standards}

\subsubsection{Indicator system}

The top runner social organization standards will have credibility and authority only by a scientific method of evaluation. So the scientific evaluation system which includes certification contents and specific indexes must be built to show the advancement of top runner social organization standards. As to certification contents, the following aspects should be considered. Firstly, the standard must have advancements of performance indexes. Social organization standards with advantages of quick responsiveness to market and innovation shall be developed to supply national standards, industry standards and local standards and fill up the blank of current standards. Social organizations are encouraged to develop standards which are stricter than national standards, industry standards and local standards in order to lead the industry and enterprise. Therefore, the advancements of performance indexes will be the first essential conditions to be top runner social organization standards. Secondly, the standard must have technical advancement. The technical advancement refers to good quality performance of product, high technological level, high reliability of automatic control equipment's and technological documents etc. Thirdly, the standard must have good guarantee capability of implement. Government standards always pay more attention to develop standards rather than to implement standards which will lead poor implement and popularization of standards. As the top runner social organization standards, good guarantee capability of implement will be necessary for the standards' implement and popularization. Fourthly, the standards must have good benefits of implement after implement and popularization. The benefits include economic benefits and social benefits.

\subsubsection{Certification process}

Reasonable and high-efficient certification process shall be built after the indicator system, which ensure the certification of top runner social organization standards.

Firstly, application requirement of the top runner social organization standards must be confirmed. The top runner social organization standards which are outstanding will have credibility and authority only by a scientific method of evaluation. Therefore, application requirement of the top runner social organization standards shall be stricter which assure the following evaluation. The evaluation shall be considered from four aspects corresponding to the indicator system and specific requirements shall be clear. For example, the performance index must meet the compulsive standards, laws and regulations and the technological process must meet the environmental protection and occupational health and safety etc. Technical index advancement report from institutions with corresponding qualification will be provided for evaluation. As to the standard capability of implement, it has been suggested that the standard must have implemented for 2 years or longer. Moreover, the promotion on industry criterion and development shall be obviously presented. As to benefits of standards' implement, good economic benefits and social benefits shall be brought by the standards. Quantitative assessment shall be provided in the benefit evaluation report. In addition, social organization standards applying for the top runner evaluation must be issued on the National Social Organization Standards Information Platform (the Platform For short). As to the social organizations, application requirement also should be proposed. For example, social organizations which has pass the evaluation of good practice will have priority.

Secondly, the implementation process must be clear. Experimental units may be a good choice in the initial stage. Industries with active innovation and mature technology may be prior as experimental units. Then systematic investigate and survey shall be carried out. The scope of top runner standards shall be confirmed and classified, such as product standards, service standards etc. The specific index also shall be confirmed for comparability among standards of the same kind. After the experimental units, good experiences and methods can be summarized and analyzed for the social 
organization standards top runner system's popularization throughout the country. When the top-level design is mature, the implement scheme of social organization standards top runner system shall be issued nationwide. The notification shall be printed and distributed by General Administration of Quality Supervision, Inspection and Quarantine of the People's Republic of China and Standardization Administration of the People's Republic of China. Social organizations are voluntary for applying. And the application will be received by professional third-party evaluation institution. According to different product and territory, evaluation rules shall be formulated by third-party evaluation institution. Evaluation rules must be discussed by specialists and offer to appropriate body. At last, the list of top runner social organization standards shall be opened on the Platform, supervised by the public.

\subsection{The supervision and management of top runner social organization standards}

As to approve social organization standards, sustaining and effective supervision mechanism shall be built for the authority and credibility of top runner social organization standards. The mechanism of supervision and management shall be carried out from three aspects of stimulation mechanism, supervision mechanism and update mechanism.

\subsubsection{Stimulation mechanism}

As the list of top runner social organization standards shown on the Platform, it will set an good example for the same industry. Meanwhile, the top runner organizations will be accepted by public. The special column of top runner system is necessary on the Platform, in order to promote the top runner social organizations and products. It is encouraged that top runner organizations play a role in national standards and international standards' development and revision. Top runner social organization standards which is in the scope of national standards are recommended to transform to national standards, industry standards and local standards. As to top runner products, the sign of top runner can be pasted on the packaging of products. It is suggested that the top runner standards be publicized and reported by television, internet, books, magazines, newspapers etc.

\subsubsection{Supervision mechanism}

Market supervision, same industry supervision, government supervision should be combined to form the supervision mechanism. The consumers and competitors of the same industry can supervise the top runner social organization standards. Selective examination of the top runner social organization standards is very necessary for the quality of the top runner standards.

\subsubsection{Update mechanism}

Dynamic management mechanism must be built for the top runner social organization standards' sustaining guidance. For example, the top runner social organization standards shall be audited every two years. If the social organizations update the standards, the certification process shall be restarted. Then the approved standards will be new top runner of this year.

\section{Proposal of social organization standards top runner system' third-party evaluation}

The first problem to be solved is the main body of evaluation when the social organization standards top runner system is mentioned. Social organization standards are produced by the market mechanism. And the development of social organization standards will meet the demand of market and innovation. So, as to the management of social organization standards, the government shouldn't set administrative licensing. Social organizations should develop standards independently and essential guidance, norm, and supervision shall be taken by government. Therefore, as to the evaluation of top runner social organization standards, the government impression shall be little. The evaluation shall be carried out by the market mechanism. So the third-party evaluation institutions should be independent from government and social organizations, who are organization that conforms to relevant national regulations, has corresponding qualifications and capacity and carries out evaluation of top runner social organization standards. The operation management of the evaluation organizations shall be independent and have some permissions for resources. The evaluation institutions shall have corresponding professional technical capability and excellent professional ethics. Evaluation institutions shall develop evaluation activity rules and publish the rules on the National Social Organization Standards Information Platform, in order to follow the principle of open 
and transparency.

\section{Conclusion}

Social organizations standardization, with advantages of adaptation, quick responsiveness to market, flexible intellectual property policy and effective promotion is the important direction of standardization system reform. Social organization standards top runner system will bring new vitality to the development of social organizations standards. It is considered that China's social organizations standardization is in the initial stage. There are still many fields that need explore and perfect. Social organization standards top runner system will be necessary and feasible with such a background. This paper is aimed at researching and analyzing the working framework of China's social organization standards top runner system from three aspects of definition and scope, certification process and indicator system, supervision and management mechanism with the enlightenment of foreign and domestic top runner systems. And the the third-party evaluation mechanism of social organization standards top runner scheme is discussed and analyzed.

\section{Acknowledgements}

This research was financially supported by Standardization Administration of the People's Republic of China project <Research on Management Operation of National Social Organization Standards Information Platform>(Project Number:572016B-4939).

\section{References}

[1]. Zheng-hu PANG. Organization Standards Have Bright Propects[J]. China Environmental Protection Industry, 2016, 222(12): 24-27

[2]. Yu-jie WANG, Xue BAI, Kuan CAI. Research on Foreign "Top Runner" System [J]. China Standardizations, 2016, 477(6): 122-125 